\title{
Stability Analysis of Distributed Multi-Converter System
}

\author{
M. Zadeh, M. Molinas \\ Department of Electrical Power Engineering \\ Norwegian University of Science and Technology-NTNU \\ O. S. Bragstads plass 2E, 7491 Trondheim, Norway \\ Phone number: +47 735 90454, e-mail: mehdi.zadeh@ntnu.no, marta.molinas@ntnu.no
}

\begin{abstract}
This paper discusses dynamic stability and performance of current control scheme for parallel connection of pulse-width modulated (PWM) voltage source converters (VSCs) fed by distributed energy recourses (DERs) across the distribution level of power grid. The controller has feedback compensation and limits the current harmonics while featuring fast regulation for multi-converter system. The controller enables islanded and grid-connected operations of DERs, dynamically. The load dynamics will be included in the stable control loop to provide perfect regulation of the voltage at the point of common coupling (PCC). The current controller is tested under the considerations of system delays. In the islanded mode, one of the controllable units provides voltage and frequency control as a master controller and the other units operate based on the grid-connected control strategy. The stability assessment of the system is presented based on a detailed simulation. The simulation results show that the controller for the islanded two-parallel controllable DER can ensure the stability of the system when converters are tied together. In the other hand, the weakness of the current control based method is drawn out while mismatch coupling condition.
\end{abstract}

\section{Key words}

Voltage source converters (VSCs), distributed energy recourses (DERs), multi-converter system, grid-connected

\section{Introduction}

The controllable distributed energy recourses (DERs) are interfaced to the grid through power electronics (PE) controllers and energy storage systems [1]. In this context, the controllable unit can operate in grid-connected mode or islanding mode and benefits both the grid and user ends such as an autonomous AC microgrid [2,3]. Stability of microgid in islanded mode and seamless transition between two main modes are prerequisite of modern electric supplies and auxiliary power distribution system in smart grid. Development of microgrid in such systems depends on the arrangement of interfacing converters [46].

Microgrid with interfacing multi-converter system is advantageous since a multiple DER significantly improves failures [7]. Compared to a single unit, the multi-converter system could have more capacity and control flexibilities to ensure system requirement respect to the reliability and power quality (PQ) in case of feeding largely nonlinear loads. Energy management is another opportunity for optimizing the renewable systems through the hybrid controllable DERs, leading to increased energy efficiency and lower hardware costs [7].
The most important problem in the radial configuration under presence of multiple DER units is the complexity of the control system. In this context, the plug and play feature is the key to ensure that the installation of additional interfacing inverters will not change the stability of exiting units in the system. An efficient approach to realize such performance is the frequency control by the terms parallel operation of inverters, which was firstly introduced in [8] for parallel uninterruptible power supply (UPS) applications. Obviously in such a complex system the stability analysis of this control system is an important issue as discussed in [9] subject to technical issues.

From the point of view of stability, conventional methods cannot ensure the stable operation of autonomous systems, the high depth of penetration of distributed units necessitates control provisions for autonomous operation of different kinds of distributed generation [10]. The autonomous operation of multi-converter system requires complicated controller because of uncertainties in such a multi-input multi output (MIMO) system. Consequently, all of the previously discussed methods are effective just in a limited range of operation which addresses the term "control bandwidth" [11].

Bear in mind, most renewable sources such as photovoltaic cells and small wind turbines are likely lowpower capacities at a low-voltage, this type of microgrid is considered in this paper. In a low-voltage (LV) microgrid, the power control is subject to weak transient due to the power coupling among different units when additional inductance is not exited, and it is highly affected by the coupling condition in existence of coupling inductance or LCL filter [12]. Regarding the dynamic stability, the different impedances between converters and the mismatch between different prototypes affect the stability of the system during grid-connected operation mode [13] and the power sharing during islanding mode [14].

The reactive power accuracy is further weakened if local loads are at the converter terminals. The virtual power frame transformation is presented [15] in order to avoid the power control coupling. Another way to avoid the power coupling is to control the inverter with virtual impedance method [16]. Taking to account that this method could increase the reactive power control and 


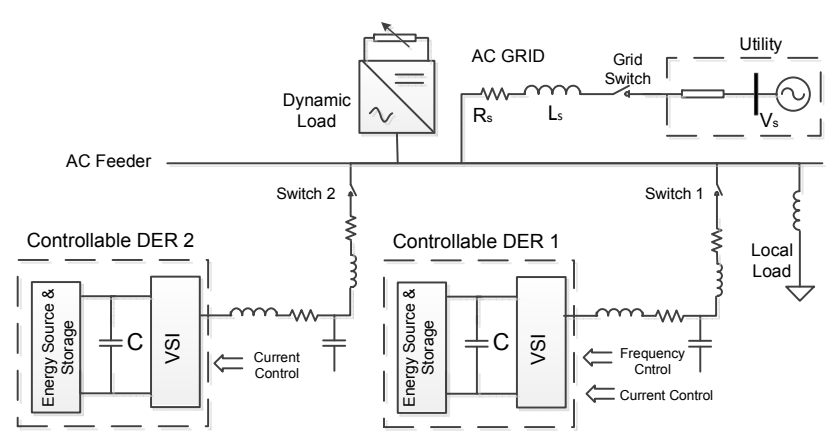

Fig. 1. Microgrid system with power electronics controlled DERs

sharing error due to the increased impedance voltage droops. Furthermore, this method does not incorporate load dynamics in the droop control loop [17]. The decoupling error method using additional control was proposed to improve the reactive power sharing accuracy [18]. However, in this method increased control complexity and harmonic current could be disadvantages, especially in presence of distorted load current. A comprehensive control strategy for the fast load changes in the autonomous operation mode of inverter is presented in [19]. This method is for an islanded converter system based on load dynamic.

The multi-converter structure increases the complexity of power and voltage control. In this direction, wireless communication is the key to the arrangement of controllers. In addition, power and frequency droop power control methods have been implemented in order to realize dispatchable characteristic of the system [6]. This paper investigates performance and stability evaluation of grid connection and islanded modes of parallel DER interfacing inverters. Based on the employed control strategy, one of inverters fulfills voltage and frequency control as a master controller for the whole system and other units regulate the delivered power in order to maintain constant average active and nonnative components of demanded power by slave controllers.

A DER unit that is equipped by the master controlled inverter is likely a matchable distributed resource with "plug and play" performance, practically offshore wind, while the slave controlled units are fairly fixed generations to supply a fix amount of load demand such as energy storage units. The matchable (operating for peak matching and load following) unit is employed to quickly stabilize the distribution system upon disconnection of the grid. In fact, the slave unit or fixed power unit is as a dynamic load and source of disturbance for the master controller. In this paper, the controller of [19] is used by the master controller and the method of [20] is used by the slave controller.

The extraction of the control signals is done in synchronous reference frame (SRF). The performance of the controller respect to the uncertainties is tested based on the time and frequency-domain analysis on a lowvoltage (LV) microgrid system. Smooth transition to the autonomous mode is explored as well. The system operation in different cases is proved through simulation studies, in the PSCAD/EMTDC software environment, conducted on a detailed switched model of VSCs in a lowvoltage multi-unit microgrid.

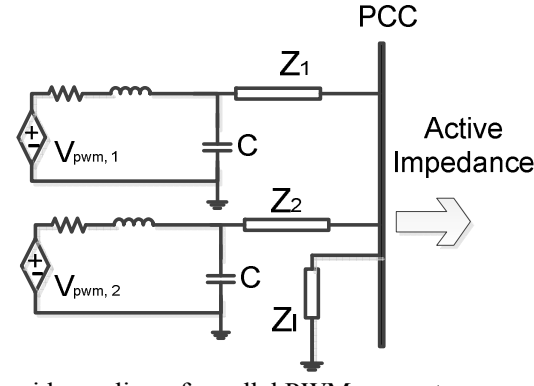

Fig. 2. Soft grid coupling of parallel PWM converters.

\section{System Structure}

The test system as shown in Fig. 1; consists of two controllable DER units employed in the microgrid connected to the utility at the point of common coupling (PCC). The microgrid can be disconnected from the main grid after half a cycle in the utility interruption or any event. Each controllable unit includes an energy source, an energy storage system, and a grid-interfacing VSC. In Fig. 1, Unit-1 has a master controller for voltage and power support, and Unit-2 is adjusted by the current control scheme. The microgrid can operate in gridconnected or islanding mode. In the grid-connected operation, the microgrid is connected to the utility, and the DER systems in the microgrid provide the local loads as well as power support for the whole grid. Once transferred to islanding operation, the DERs must immediately share the changed power demand and continue supplying power to all kinds of loads within the microgrid.

In the presence of a data communication from a central control unit to the converter units, advanced synchronization that guarantees a perfect match of both voltage magnitude and phase angle could be realized, where the synchronization reference signal can be sent from the central control to the controller [21]. The LC filter is used for voltage disturbances of each unit and the series inductance also represents the leakage inductance of the coupling transformer. Parameters of the multi-unit system are summarized in the Appendix.

\section{A. Dynamic Modelling}

In the grid-connected mode by the multi-converter system is dominated by the grid while in islanded mode the impedance seen from feeder is active (Fig. 2). The drawn part of the microgrid of Fig. 1 includes currentcontrolled VSCs in which control block diagram in the $d q$ frame is outlined in the following section. The employed control method is carried out in the $d$ - and $q$ axis models of the VSC AC-side dynamics considering the coupling terms [19]. The Proportional-Integral (PI) compensators in both $d$ - and $q$-axis are used properly in the decoupling scheme [22]. Further, the feed-forward scheme is provided to mitigate the impact of voltage and load disturbances on two axis currents; $i_{d}$ and $i_{q}$. In the feed-forward loop, dynamics of the system is considered as a filter which can be tuned based on the performance of transducers and data communication system as well as noise filters. The PI compensators in $d$ and $q$ axis respectively $h_{d}(s)$ and $h_{q}(s)$ are defined same in this case as follows.

$h_{d q}(s)=k_{p}+\frac{k_{i}}{s}$ 


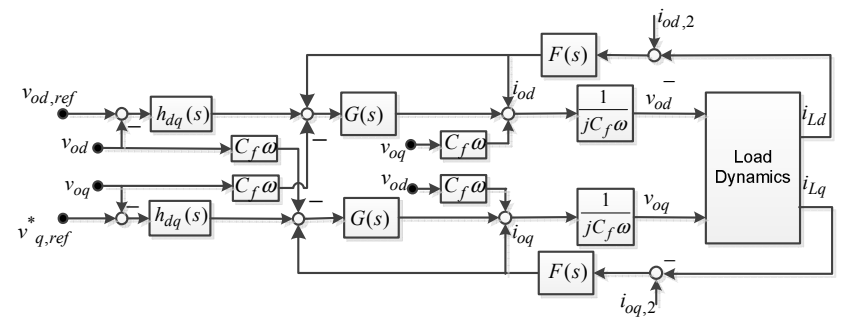

Fig. 3. Control block of master controller for multi-unit microgrid in SRF.

Where $k_{p}$ and $k_{i}$ are proportional and integral parameters of the compensator. The transfer function in SRF for current controller is selected based on the first order transfer function in [19] which is given in (2).

$$
G_{i}(s)=\frac{1}{\tau_{i} s+1}
$$

Then, Laplace transform of current components are achieved.

$$
\begin{aligned}
& I_{d}(s)=G_{i}(s) I_{d, r e f}(s)=\frac{1}{\tau_{i} s+1} I_{d, r e f}(s) \\
& I_{q}(s)=G_{i}(s) I_{q, r e f}(s)=\frac{1}{\tau_{i} s+1} I_{q, r e f}(s)
\end{aligned}
$$

Where $\square_{i}$ is the time-constant for the current controller. The set-points are defined by voltage control blocks and load dynamics. Dynamics of the voltage is termed by the following state-space equations.

$$
C_{f} \frac{d}{d t} v_{o}=i_{i n v}-i_{o}
$$

Considering space-phasor model in SRF, obtains:

$$
\begin{aligned}
C_{f} \frac{d}{d t}\left(v_{o d}+j v_{o q}\right) e^{j \theta} & \\
& =\left(i_{i n v, d}+j i_{i n v, q}\right) e^{j \theta}-\left(i_{o d}+j i_{o q}\right) e^{j \theta}
\end{aligned}
$$

The time-domain equation with separating the real and imaginary components, deduces:

$$
\begin{aligned}
& C_{f} \frac{d}{d t} v_{o d}=\left(C_{f} \omega\right) v_{o q}+i_{d}-i_{o d} \\
& C_{f} \frac{d}{d t} v_{o q}=\left(C_{f} \omega\right) v_{o d}+i_{q}-i_{o q}
\end{aligned}
$$

Where $\omega$, the angular frequency of the output voltage, and $\theta$ is the angle between the stationary and the rotating frame sensed by the Phase Locked Loop (PLL) system. The overall control of the islanded DER unit is performed in SRF that makes the angle $\theta(t)$ against the fixed frame. Therefore, the frequency of all the variables is imposed by the voltage controlled oscillator (VCO) as drawn in (7) [19].

$$
\frac{d \theta}{d t}=\omega(t)
$$

The master controller supplies the load directly in islanded mode and in contribution in grid connected mode. The load components in SRF, $i_{L d}$ and $i_{L q}$ are viewed as the nonlinear, dynamic system in which the inputs are $v_{q}$ and $v_{d}$ :

$$
\begin{aligned}
& {\left[\begin{array}{l}
i_{L d} \\
i_{L q}
\end{array}\right]=\left[\begin{array}{l}
g_{1}\left(x_{1}, x_{2}, \ldots, x_{n}, v_{s d}, v_{s q}\right) \\
g_{2}\left(x_{1}, x_{2}, \ldots, x_{n}, v_{s d}, v_{s q}\right)
\end{array}\right]} \\
& \frac{d x_{i}}{d t}=f_{i}\left(x_{1}, x_{2}, \ldots, x_{n}, v_{s d}, v_{s q}\right)
\end{aligned}
$$

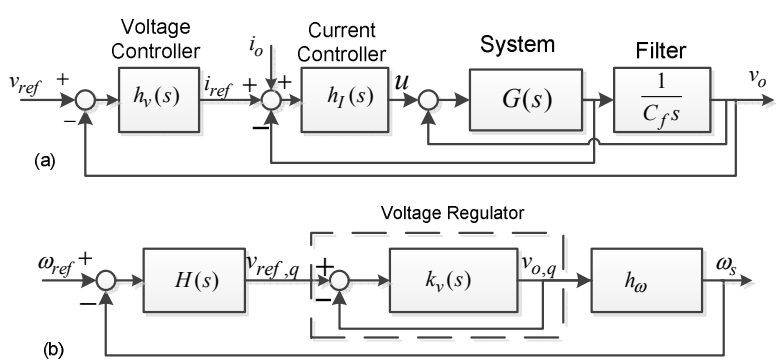

Fig. 4. Closed loop control block diagrams for the; (a) voltage, (b) PLL

Where $x_{i}$ variables are the state variables of the load while $g$ and $f$ are nonlinear functions of their arguments. $i_{L d}$ and $i_{L q}$ are, in turn, the responses of the $d$ - and $q$-axis current controllers of the VSC system to $i_{d, r e f}$ and $i_{q, r e f}[20]$. The control system for load and voltage regulation is drawn in Fig. 3 as will be discussed in the following section.

\section{Control System}

A current-control scheme establishes the core of the control scheme of the VSC. The function of the current control scheme is to regulate the $d$ - $q$ components of the ac-side current by means of the pulse-width modulation (PWM) switching strategy for three leg switches. In the scheme, which can be applied for the continuous- and discrete- time model, the dynamic behavior of output three phase currents $i_{a b c}$ is described by the space-vector equation [19].

$L \frac{d}{d t} \overline{i_{L}}=-R_{t} \overline{i_{L}}+\overline{v_{t}}-\overline{v_{o}}$

Where $\overline{i_{L}}, \overline{v_{t}}$ and $\overline{v_{o}}$ are the space-vector representations output current, terminal voltage for each converter unit and output voltage at the PCC. The VSC terminal voltage is controlled by the modulation vectors in terms of its $d q$ frame component:

$$
\begin{aligned}
& m(t)=\left(m_{d}+j m_{q}\right) e^{j \theta} \\
& v_{t}(t)=\left(v_{t d}+j v_{t q}\right) e^{j \theta} \\
& \left(v_{t d}+j v_{t q}\right) e^{j \theta}=\frac{V_{D C}}{2}\left(m_{d}+j m_{q}\right) e^{j \theta}
\end{aligned}
$$

The SRF control of the real and reactive power controller assuming a steady operating point with a fixed angular frequency of $\omega_{\text {ref }}$ we have:

$L_{i} \frac{d}{d t} i_{L_{i}, d}=L \omega_{r e f} i_{q}-R_{t} i_{d}+v_{t d}-v_{o d}$

$L_{i} \frac{d}{d t} i_{L_{i}, q}=-L \omega_{r e f} i_{d}-R_{t} i_{q}+v_{t q}-v_{o q}$

In which, $v_{t d}$ and $v_{t q}$ are expressing the VSC model in SRF as:

$v_{t d q}=\frac{V_{D C}}{2} m_{d q}$

In this model $i_{d}$ and $i_{q}$ are state variables while $v_{t d}$ and $v_{t q}$ are control inputs, and $v_{o d}$ and $v_{o q}$ are disturbance inputs. To decouple the dynamics, we determine $m_{d}$ and $m_{q}$ as:

$$
\begin{aligned}
& m_{d}=\frac{2}{V_{D C}}\left(u_{d}-L \omega_{r e f} i_{q}+v_{o d}\right) \\
& m_{q}=\frac{2}{V_{D C}}\left(u_{q}+L \omega_{r e f} i_{d}+v_{o q}\right)
\end{aligned}
$$


Where $u_{d}$ and $u_{q}$ are additional control inputs for scheme. In the islanded mode, the network frequency regulation spots down to the control of the output voltage [23].

\section{A. Inner Voltage and Current Control}

The current-control is the innermost part of the DER control system. Based on the modified current control in [19], the load voltage, $V_{a b c}$, must be regulated with load dynamic uncertainties. The regulation task involves the control of both frequency and voltage. The reference voltage for the phase-angle is voltage of PCC. In the case that the grid is not connected, the control system can follow the voltage of the PCC and provides the power for the load in islanded mode. The PCC line to natural voltage is given by:

$\left|v_{o}\right|=\sqrt{v_{o d}^{2}+v_{o q}^{2}}$

Where the reference frame is rotating by the angular frequency of $\omega$. Since $v_{o q}$ is supposed to be zero in steady state, so the regulation of the voltage is related to the $v_{o d}$. In the transient states, the frequency can be controlled by $v_{o, q}$. The Fig. 4 (a) indicates the closed loop control scheme, in which the filter $h(s)$ is the compensator for SRF control loop. In the control loops feed-forward signals are utilized to eliminate the coupling between voltages in SRF. The reference values in this control loop are adjusted based on the model in Fig. 3. The filter $F(s)$ in the Fig. 3 represents the measurement for $i_{d}$ and $i_{q}$ which are included in the control signals. Feed-forward signals are used to mitigate the impact of the load dynamics on voltage regulation. The output current of the control is given:

$i_{d, i s}=u_{d}-\left(C_{f} \omega_{r e f}\right) v_{o q}+i_{d}$

$i_{q, i s}=u_{q}-\left(C_{f} \omega_{r e f}\right) v_{o d}+i_{q}$

Substituting for $i_{\text {dref }}$ and $i_{\text {qref }}$, obtains:

$I_{d}=\frac{1}{\tau_{i} s+1} U_{d}-\frac{1}{\tau_{i} s+1}\left(C_{f} \omega_{r e f} V_{o q}\right)+\frac{1}{\tau_{i} s+1} I_{d}$

$I_{q}=\frac{1}{\tau_{i} s+1} U_{q}+\frac{1}{\tau_{i} s+1}\left(C_{f} \omega_{r e f} V_{o d}\right)+\frac{1}{\tau_{i} s+1} I_{q}$

Taking Laplace transform from both equations, gives:

$C_{f} s V_{o d}=\frac{1}{\tau_{i} s+1} U_{d}+C_{f} \omega_{r e f} \frac{\tau_{i}}{\tau_{i} s+1} V_{o q}-\frac{\tau_{i}}{\tau_{i} s+1} I_{d}$

$C_{f} s V_{o q}=\frac{1}{\tau_{i} s+1} U_{q}-C_{f} \omega_{r e f} \frac{\tau_{i}}{\tau_{i} s+1} V_{o d}-\frac{\tau_{i}}{\tau_{i} s+1} I_{q}$

Considering the first order transfer function included in the current control process, we can eliminate the DC gain resulting a new function which has a zero DC gain $\left(\frac{\tau_{i}}{\tau_{i} s+1}\right)$. In this explanation, transient terms deteriorate to zero in the steady-state. To make the transient terms faster, time constant $\tau_{i}$ must be chosen to be small. Those equations are valid also under variable-frequency conditions while $\square$ is not constant, and considered as a control variable. The block diagram of Fig. 4 (a) can be used for the compensator design for two decoupled SISO systems. Each control loops includes a PI compensator:
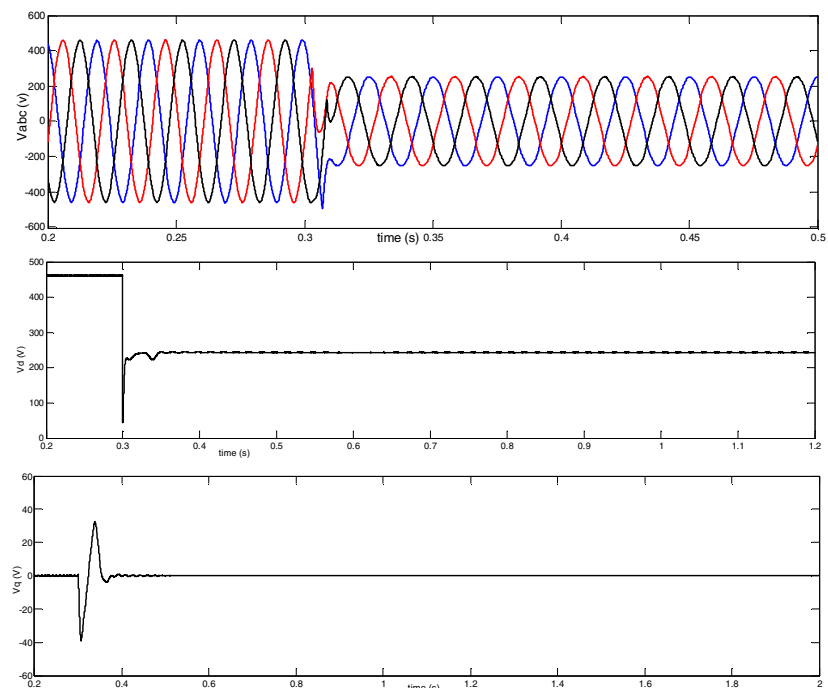

Fig. 5. Three phase voltage waveforms at PCC upon islanding transition and Voltage response of the multi-unit system.

$h_{d q}(s)=k_{p}+\frac{k_{i}}{s}$

The controller is designed using the SISO methods. The designed controller provides sufficient robust stability margins for the overall closed loop system [24].

\section{B. Frequency Control}

In the Fig. 4 (b), $v_{\text {qref }}$ is issued by another control loop to regulate $\omega$. For this loop, the compensator $k_{\omega}(s)$ can be a pure gain or a PI compensator. This however results in no steady-state error and includes the overall voltage control:

$H_{v}(s)=\frac{V_{o q}(s)}{V_{\text {oqref }}(s)}$

The PLL gets $v_{o, q}$ through the filter $H(s)$ and gives the $\omega$, then the angle is obtained from the $\omega$ in the grid connected mode. The $\omega$ in islanded mode will be equal in steady state to the $\omega_{\text {ref }}$ as the reference frequency of the network. In the base frequency in steady state, $v_{o, q}$ becomes equal to zero. The PLL is described by:

$H(s)=\frac{\Omega(s)}{V_{o, q}(s)}$

The objective is achieved by the closed-loop structure illustrated in Fig. 4 (b). The transfer function of the closed loop frequency regulation can be formulated as:

$H_{\omega}(s)=\frac{\Omega(s)}{\Omega_{r e f}(s)}=\frac{h_{\omega} \cdot H(s) \cdot h_{v}(s)}{1+h_{\omega} \cdot H(s) \cdot h_{v}(s)}$

The control strategy ensures fast regulation over both the frequency and the magnitude of the output voltage. In a multiunit application, the set points $\omega_{\text {ref }}$ and $v_{o, r e f}$ of each converter are drooped against the power changes. The power components are calculated from the load current and the controllable unit based on the power sharing. The calculated values are low pass filtered to set the average power as reference points for frequency and magnitude as follows [8]:

$\omega_{r e f}=f_{p-f}(P)=\omega_{r}-m\left(P_{r}-P\right)$
$v_{d, r e f}=f_{q-v}(Q)=\omega_{r}-m\left(Q_{r}-Q\right)$ 
(a)

(b)
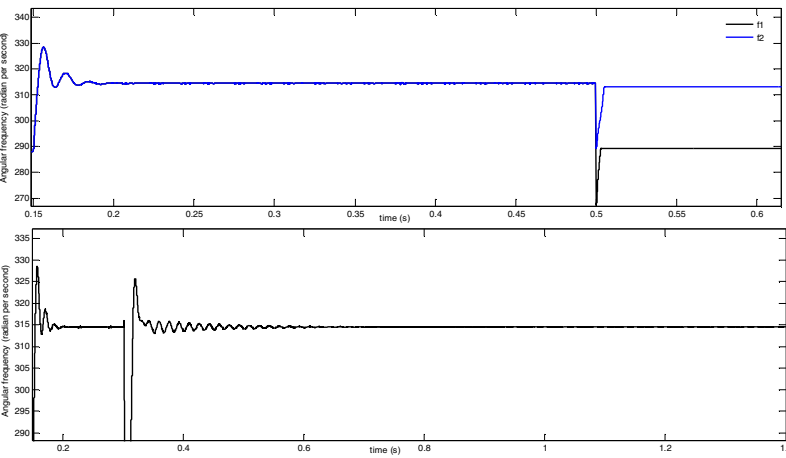

(c)

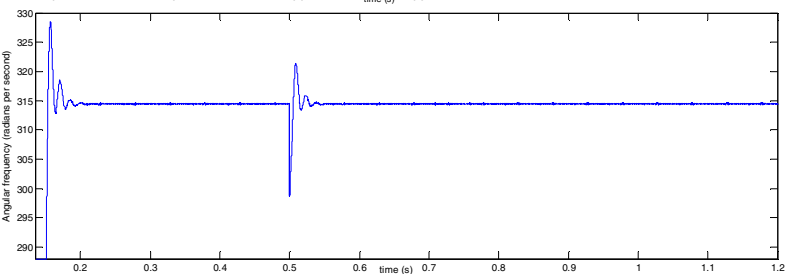

Fig. 6: Frequency response of the multi-unit system; (a): fixed frequency, (b): normal PLL (c): frequency regulation.

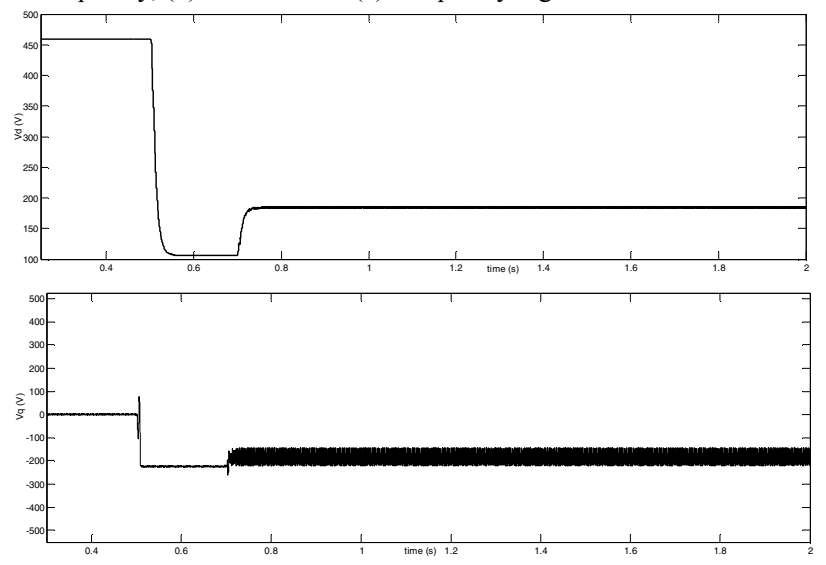

Fig. 7: Dynamic response of the voltage at PCC

\section{Simulation Results}

To study the stability of the controlled inverters, the LV microgrid with two parallel controllable units is examined (the system of Fig. 1). Both units are equipped with the current controller and the Unit-1as matchable DER regulates the voltage at the PCC as well. Different case studies are carried out as detailed in this section in cases of transition to the islanded mode, sensitivity to the delayed islanded detection, voltage and frequency tracking for different reference frequency determinations and further, instabilities caused by the mismatch in the microgrid configuration.

\section{A. Transition between Two Modes of Operation}

Toward a stable transition from the grid-dominant to the pure inverter supply, the adopted controller is responsible to provide the frequency synchronization in the multi-unit system. In the grid-connected mode, each unit operates as a current-controlled VSC [20]. After an islanding event and upon islanded detection, the matchable unit activates the master controller to regulate the voltage and frequency of the remained network. The load behavior directly affects the transfer function in the autonomous mode. Fig. 5 shows the voltage response for the PCC upon an islanded event.
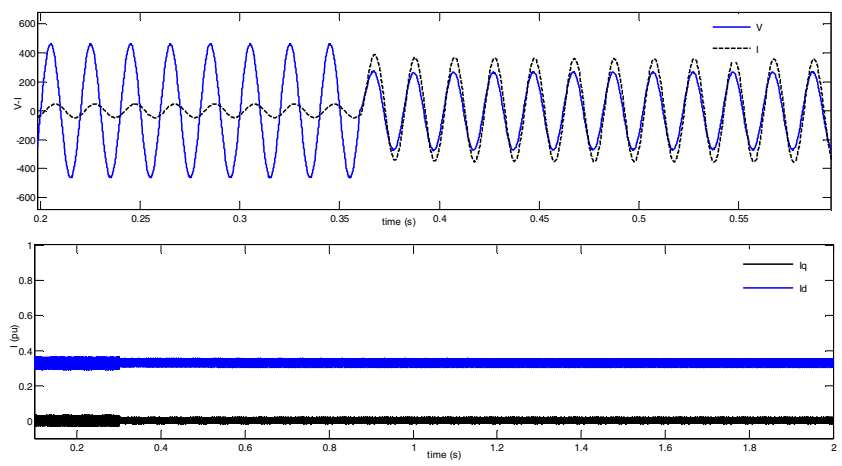

Fig. 8. Voltage and output current of Unit-1 (upper) and dynamics of the current components for Unit-2 in $d q$ (lower).

Due to the different condition, the PCC voltages have to be settled down to the new reference value during the transition process. The results of Fig. 5 verify the feasibility of the transition phenomenon in the twoparallel unit system. Fig. 6 shows the frequency response of the multi-unit system during the transition. The Fig. 6 (a) illustrates the angular frequency of the output voltage while the frequency is fixed in islanded mode.

In this approach, $f_{1}$ is reduced frequency to supply a non-sensitive load and maintaining the voltage in desired value. The frequency $f_{2}$ is a fixed reference frequency equal to the grid frequency while the power configuration is practically matched to the previous state. The Figs. 6 (b) and (c) show the frequency response in two different frequency synchronization methods. In the upper case, the frequency is observed by a normal PLL provided in PSCAD and the lower figure shows the result from the frequency controller as depicted in Fig 4 (b). Seeing figures 5 and $6(\mathrm{~b}) ; v_{q}$ and $\omega$ remain constant subsequent to the changes in $v_{s d}$ which is due to the dynamic decoupling strategy.

\section{B. Reference Voltage Tracking}

The voltage control is supposed to set the magnitude at a constant value across the $\mathrm{AC}$ feeder. But, the reference voltage is changed in this simulation case in order to test the stability in voltage dynamics. The reference voltage steps down and up and results in Fig. 7 indicate the voltage components in SRF tracking the reference. Fig. 7 shows the response of two unit system without $v_{q}$ feedback loop and through a stepwise change in reference value. The Unit-2 normally injects a portion of the load current while the matchable DER unit regulates the PCC voltages at the constant value and delivers the load with the remainder of its demanded current in islanded mode as shown in Fig. 8. The results illustrate the response of the islanded system in the partially-loaded and full-load condition. Since the slave controller operates in current control mode, its output currents are not affected by the voltage after islanded detection. However, the master controller currents change significantly to provide the load with its demanded power continuously.

Subsequent to voltage changes, transient voltage and current are seen, in short time. However, the voltage and current transients are within the acceptable limits. The results of Figs. 7 and 8 indicate the stable response of the two-parallel DER system to the adopting current control scheme. The static unit has capability of saving power in 


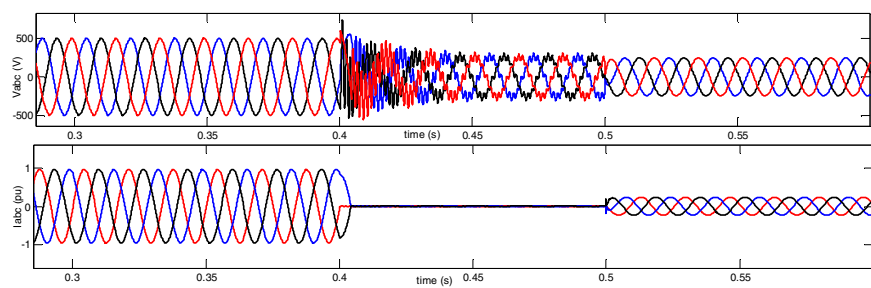

Fig. 9. Voltage and output currents

distributed energy storages while partially load. In the other hand for increased load demand the additional power can be supplied by the storage system. As shown in Fig. 8, the Unit-2 keeps its previous state regarding power flow.

\section{Undetected Events}

When the islanding mode is detected after a time delay, the frequency of the system is oscillating and the current injected by the master controller is likely to be zero during the interval time. At time instant $t=0 \triangleright 4 \mathrm{~s}$, the main switch is opened, but the islanding is detected and operated at $\mathrm{t}=0.5 \mathrm{~s}$. As shown in Fig. 9, after switching the PCC voltage waveform is highly distorted because of the frequency variation and instability in PLL. Due to the lack of voltage regulation, the magnitude of the PCC voltages slightly fluctuates immediately after the islanding event and prior to the control transfer instant.

\section{Instabilities and Stable Region}

The voltage and current waveforms of coupled two unit system in case of mismatch coupling condition are shown in Fig. 10. The controller parameters are likely to be varied to find the new point that the single unit system has a sufficient stability. Initially, the switch-1 (Fig. 1) is close, Unit-1 is operating and providing the load demand in a lower rating. At the instant $t=0.5 \mathrm{~s}$ the switch- 2 is closed and the Unit-2 is contributes in supplying the load. The harmonic spectrum of the output current produced by the master converter is shown in Fig. 11. This figure shows the sub-harmonic occurred in the output current components in case of parallel converters. The subharmonic content is significantly higher than the reference frequency of the system. Such instability is due to the coupling of tied inverters with different inductors.

It depends on the component tolerance variation in the controller limits (in this case $2 \%$ inductance variation is allowed). Design parameters outside of this limitation are avoided because of the lack of coupling requirements. Further definitions are respect to the determination of stability margin for coupling of parallel converters against the grid or in autonomous mode.

\section{Conclusion}

Dynamic analysis of the autonomous operation of parallel connected DER interfacing converters has been presented in this paper. Based on the control strategy, the master controller regulates the voltage and frequency of the islanded system and other units as the static units are responsible for the power flow using grid tied power control in SRF. The system stability and robustness of the control scheme has been tested in a multi-unit microgrid

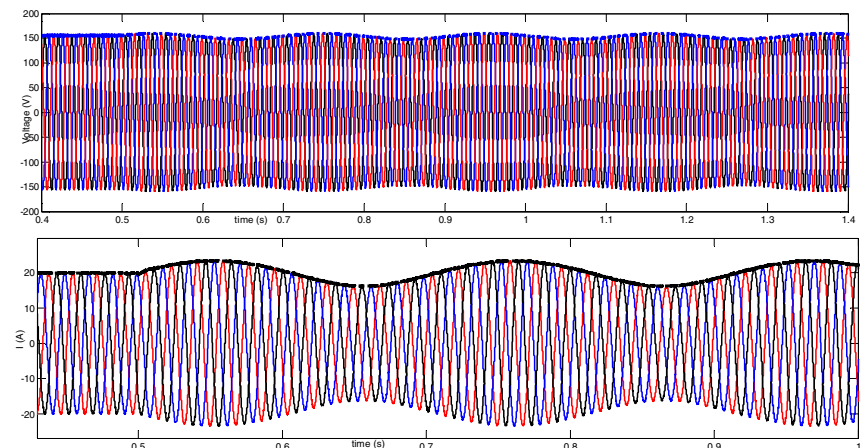

Fig. 10. Voltage and current waveforms of the inverter output in Unit-1.

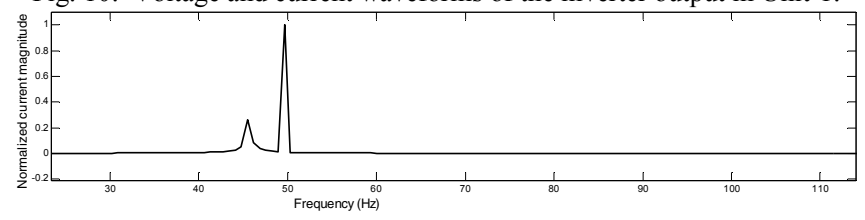

Fig. 11. Spectrum of the inverter current for Unit-1.

system. The performance analysis has been done in different cases such as transition performance, frequency regulation and dynamic stability evaluation. Given the stability of power coupling in the proposed scheme, exemplification is then provided for the mismatch coupling condition, when each unit has its specific coupling impedance. In this case, the network has a stability margin which depends on the impedance configuration and limited further by the control bandwidth.

\section{Appendix}

Parameters of each DER unit and the utility system which are used in this study are summarized in Table I.

TABLE I

SYSTEM PARAMETERS FOR THE MICROGRID IN FIG. 1

\begin{tabular}{|l|l|}
\hline Quantity & Value \\
\hline Grid Voltage $\left(V_{\text {opeak }}\right)$ & $500 \mathrm{~V}$ \\
\hline Grid inductance $(L)$ & $10 \% \mathrm{p} . \mathrm{u}$ \\
\hline Line inductance $\left(L_{l}\right)$ & $20 \% \mathrm{p} . \mathrm{u}$ \\
\hline Line inductance $\left(L_{2}\right)$ & $25 \% \mathrm{p} . \mathrm{u}$ \\
\hline Grid frequency $(f)$ & $50 \mathrm{~Hz}$ \\
\hline Output filter capacitance $\left(C_{f}\right)$ & $45 \% \mathrm{p} . \mathrm{u}$ \\
\hline Filter inductance $\left(L_{f}\right)$ & $15 \% \mathrm{p} . \mathrm{u}$ \\
\hline Total output resistance $\left(R_{t}\right)$ & $2 \% \mathrm{p} . \mathrm{u}$ \\
\hline Carrier frequency $\left(f_{s w, I, 2}\right)$ & $10 \mathrm{kHz}$ \\
\hline Sampling frequency $\left(f_{s}\right)$ & $10 \mathrm{kHz}$ \\
\hline DC buses voltage $\left(V_{d c}\right)$ & $1600 \mathrm{~V}$ \\
\hline
\end{tabular}

\section{References}

[1] J. M. Carrasco, L. G. Franquelo, J. T. Bialasiewicz, E. Galvan, R. C. P. Guisado, M. A. M. Prats, J. I. Leon, and N. Moreno-Alfonso, "Power electronic systems for the grid integration of renewable energy sources: A survey, " IEEE Trans. Power Electron., vol. 53, no. 4, pp. 1002-1016, Aug. 2006.

[2] Bloemink, J.; Iravani, M.R.; , "Control of a Multiple Source Microgrid With Built-in Islanding Detection and Current Limiting," IEEE Trans. on Power Delivery, vol.27, no.4, pp.2122-2132, Oct. 2012.

[3] N. Pogaku, M. Prodanovic, and T. C. Green, "Modeling, analysis and testing of autonomous operation of an inverterbased microgrid," IEEE Trans. on Power Electron., vol. 22, no. 2, pp. 613-625, Mar. 2007.

[4] R. Lasseter, "Microgrids," in Proc. IEEE PES Winter Meeting, 2002, pp. 305-308. 
[5] M. Barnes, J. Kondoh, H. Asano, J. Oyarzabal, G. Ventakaramanan, R. Lasseter, N. Hatziargyriou, and T. Green, "Real-world microgrids-An overview," in Proc. IEEE Int.Conf. System Eng., April 2007,pp. 1-8.

[6] Katiraei and M. R. Iravani, "Power management strategies for a microgrid with multiple distributed generation units," IEEE Trans. Power Systems, vol. 21, no. 4, pp. 1821-1831, Nov. 2006.

[7] P. Piagi and R. H. Lasseter, "Autonomous control of microgrids," in Proc. IEEE PES General Meeting, 18-22 June 2006.

[8] M. C. Chandorkar, D. M. Divan, and R. Adapa, "Control of parallel connected inverters in standalone ac supply systems, " IEEE Trans. on Ind. Appl., vol. 29, no. 1, pp. 136-143, Jan./Feb. 1993.

[9] Barklund, N. Pogaku, M. Prodanovic, C. HernandezAramburo, and T. C. Green, "Energy management in autonomous microgrid using stability-constrained droop control of inverters," IEEE Trans. on Power Electron., vol. 23, no. 5, pp. 2346-2352, Sep. 2008.

[10] Katiraei, M. R. Iravani, and P. W. Lehn, "Micro-grid Autonomous Operation During and Subsequent to Islanding Process, " in IEEE Trans. on Power Delivery, vol. 20, no. 1, pp. 248-257, Jan. 2005.

[11] Turner, R.; Walton, S.; Duke, R.; "Stability and Bandwidth Implications of Digitally Controlled Grid-Connected Parallel Inverters," in IEEE Trans. on Ind. Electrons. , vol.57, no.11, pp.3685-3694, Nov. 2010.

[12] Chien-Liang Chen; Jih-Sheng Lai; Yu-Bin Wang; Sung-Yeul Park; Miwa, H.; , "Design and Control for LCL-Based Inverters with Both Grid-Tie and Standalone Parallel Operations," in Proc. IEEE Ind. Appl. Annual Meeting, (IAS '08), pp.1-7, 5-9 Oct. 2008.

[13] Mazumder, S.K.; "Switching-sequence based global stability and control of standalone and interactive power converters," in Proc. IEEE Energy Conversion Congress and Exposition (ECCE), 2011, pp.2036-2043, 17-22 Sept. 2011.

[14] Delghavi, M.B.; Yazdani, A.; "An Adaptive Feedforward Compensation for Stability Enhancement in DroopControlled Inverter-Based Microgrids," in IEEE Trans. on Power Delivery, vol.26, no.3, pp.1764-1773, July 2011.
[15] K. D. Brabandere, B. Bolsens, J. V. D. Keybus, A. Woyte, J. Driesen, and R. Belmans, "A voltage and frequency droop control method for parallel inverters, " in IEEE Trans. on Power Electron., vol. 22, no. 4, pp. 1107-1115, Jul. 2007.

[16] J. M. Guerrero, J. Matas, L. G. Vicuna, M. Castilla, and J. Miret, "Decentralized control for parallel operation of distributed generation inverters using resistive output impedance, " in IEEE Trans. Ind. Electron., vol. 54, no. 2, pp. 994-1004, Apr. 2007.

[17] Karimi, H. Nikkhajoei, and R. Iravani, "Control of an Electronically-Coupled Distributed Resource Unit Subsequent to an Islanding Event" in IEEE Trans. on Power Delivery, vol.23, no. 1,pp.493-501, Jan. 2008.

[18] Tuladhar, H. Jin, T. Unger, and K. Mauch, "Control of parallel inverters in distributed AC power systems with consideration of line impedance effect, " in IEEE Trans. on Ind. Appl., vol. 36, no. 1, pp. 131-138, Jan. 2000.

[19] Yazdani and R. Iravani, Voltage-Sourced Converters in Power Systems, John Wiley \& Sons, 2011.

[20] Yazdani and R. Iravani, "A Unified Dynamic Model and Control for the Voltage-Sourced Converter Under Unbalanced Grid Conditions, " in IEEE Trans. on Power Delivery, vol. 21, no. 3, pp. 1620-1629, July 2006.

[21] M. Guerrero, L. G. Vicuna, J. Matas, M. Castilla, and J. Miret, "A wireless controller to enhance dynamic performance of parallel inverters in distributed generation systems," in IEEE Trans. Power. Electron., vol. 19, no. 5, pp. 1205-1213, Sep. 2004.

[22] Bajracharya, M. Molinas, Jon A. Suul, T. Undeland, "Understanding of tuning techniques of converter controllers for VSC-HVDC," Nordic Workshop on Power and Industrial Electronics, June 9-11, 2008.

[23] Delghavi, M.B.; Yazdani, A.; "Islanded-Mode Control of Electronically Coupled Distributed-Resource Units Under Unbalanced and Nonlinear Load Conditions," in IEEE Trans. on Power Delivery, vol.26, no.2, pp.661-673, April 2011.

[24] Ogata, Modern Control Engineering, Prentice Hall, Fourth Edition, 2002. 